\title{
Discharge Characteristics of Four Highway Drainage Systems in OHio
}

By David E. Straub

U.S. GEOLOGICAL SURVEY

Water-Resources Investigations Report 95-4020

Final Report on a study of Discharge Characteristics of

Selected Longitudinal Drain Materials

Prepared in cooperation with the OHIO DEPARTMENT OF TRANSPORTATION and the U.S. DEPARTMENT OF TRANSPORTATION, FEDERAL HIGHWAY ADMINISTRATION

The contents of this report reflect the views of the anthors, who are responsible for the frots and the accuracy of the dat presented herin. The contents do not necessarily refiect the official views or policies of the Ohio Department of Transpotation or the Federal Highway Administration. This Ieport does not constitute a standard, specification, of regulation.

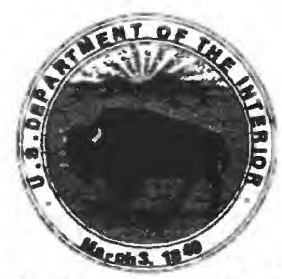

Columbus, Ohio 1995 


\title{
U S. DEPARTMENT OF THE INTERIOR BRUCE BABBITT, Secretary
}

\author{
U.S. GEOLOGICAL SURVEY \\ Gordon P. Eaton, Director
}

For additional information write to:

District Chief

U.S. Geological Survey 975 West Third Avenue

Columbus, $\mathrm{OH} 43212-3192$
Copies of this report may

be purchased from:

\section{U.S. Geological Survey}

Earth Science Information Center

Open-File Reports Section

Box 25286, MS 517

Denver Federal Center

Denver, CO 80225 


\section{CONTENTS}

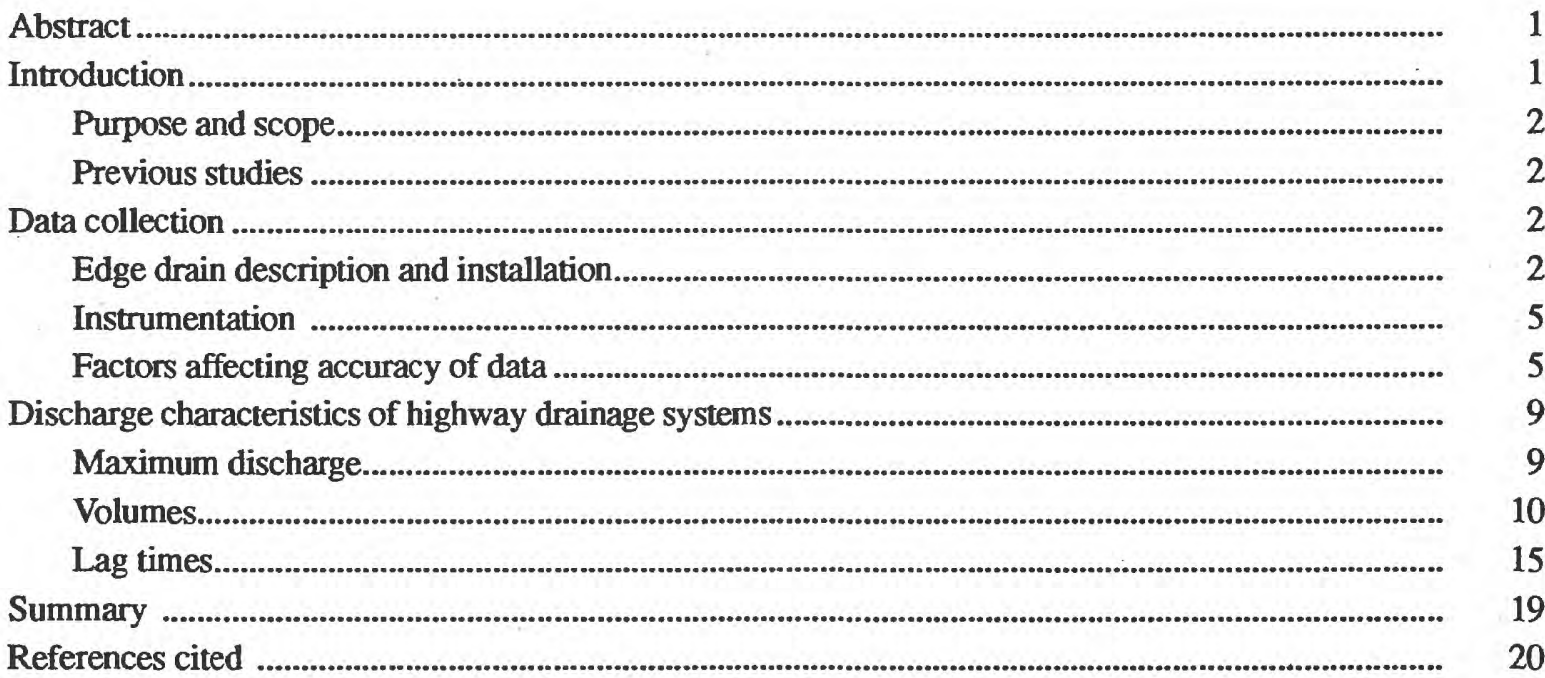

\section{FIGURES}

1. Map showing location of edge drain study site at Granville, Ohio.................................................. 3

2. Cross-sectional views and construction characteristics of edge drains used in this investigation........ $\quad 4$

3. Plan view of edge drain study site at State Route 16, Granville, Ohio ................................................. 6

4. Cross section of eastbound lane of State Route 16 at edge drain study site ........................................ 7

5. Diagram showing design of dual tipping-bucket gage.......................................................................... 8

6. Graph showing distribution of maximum discharges for each edge drain for 72 events, 1991-93 for State Route 16 near Granville, Ohio

7. Graph showing distribution of volumes for each edge drain for 55 events, 1991-93 for State Route 16 near Granville, Ohio

8. Graph showing distribution of the ratios of discharge volumes to rainfall volumes for each edge drain for 55 events, 1991-93 for State Route 16 near Granville, Ohio..................................... 14

9. Diagram showing calculated lag times ................................................................................................ 16

10. Graph showing distribution of lag times between hydrograph centroid and hyetograph centroid for each edge drain for 51 events, 1991-93 for State Route 16 near Granville, Ohio.......................

11. Graph showing distribution of lag times between rainfall onset and maximum discharge for each edge drain for 51 events, 1991-93 for State Route 16 near Granville, Ohio 2

5 9

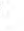
10

\section{TABLES}

1. Statistics for maximum discharges for each edge drain for 72 events, 1991-93 for State Route 16 near Granville, Ohio

2. Statistics for volumes for each edge drain for 55 events, $1991-93$ for State Route 16 near Granville, Ohio.

3. Statistics for discharge volumes as a percentage of rainfall volume for each edge drain for 55 events, 1991-93 for State Route 16 near Granville, Ohio 
TABLES (continued)

4. Statistics for lag times between hydrograph centroid and hyetograph centroid for each edge drain for 51 events, 1991-93 for State Route 16 near Granville, Ohio

5. Statistics for lag times between rainfall onset and discharge maximum for each edge drain for 51 events, 1991-93 for State Route 16 near Granville, Ohio

\section{CONVERSION FACTORS AND ABBREVIATED UNITS}

\begin{tabular}{rll}
\hline Multiply & \multicolumn{1}{c}{ By } & To obtain \\
\hline inch $(\mathrm{in})$. & 25.4 & millimeter \\
foot $(\mathrm{ft})$ & 0.3048 & meter \\
mile $(\mathrm{mi})$ & 1.609 & kilometer \\
square foot $\left(\mathrm{ft}^{2}\right)$ & 0.09290 & square meter \\
square mile $\left(\mathrm{mi}^{2}\right)$ & 2.590 & square kilometer \\
cubic foot $\left(\mathrm{ft}^{3}\right)$ & 0.02832 & cubic meter \\
cubic foot per hour $\left(\mathrm{ft}^{3} / \mathrm{hr}\right)$ & 0.02832 & cubic meter per hour \\
\hline
\end{tabular}




\title{
Discharge Characteristics of Four Highway Drainage Systems in Ohio
}

\author{
By David E. Straub
}

\section{Abstract}

Excessive water in the subbase of a highway combined with large traffic volumes and heavy loads is a major cause of road deterioration. Prompt removal of any excess water in a subbase will decrease the road deterioration and extend the effective life of a highway. This study presents discharge characteristics of four highway subbase drainage systems. These systems consisted of shallow, longitudinal trenches with geocomposite drain materials (edge drains made from a polyethylene core surrounded by a geotextile filter fabric) that underlie the joint between the shoulder and the traffic lane of State Route 16, approximately 1.0 mile southeast of Granville, Ohio. For selected rainfall-runoff events the maximum discharge, discharge volumes, and lag times for specific discharge characteristics from April 1991 through November 1993 were computed for three geocomposite productsa post type, an oblong-pipe type, and a cusp type - and a conventional perforated pipe edge drain.

In general, the discharge characteristics of the conventional edge drain and that of the oblong-pipe edge drain were similar for most of the rainfall-runoff event characteristics. Both produced most of the highest maximum discharges and largest discharge volumes among the four longitudinal edge drains. The post edge drain produced smaller maximum discharges and volumes than the conventional and oblong-pipe edge drains, but it had the shortest lag times for most of the event characteristics. The cusp edge drain produced small maximum discharges and small volumes similar to those from the post edge drain, but it had the longest lag times of all the edge drains for most of the event characteristics. The cusp edge drain may have also had some problems during installation which could have affected the discharge characteristics.

\section{INTRODUCTION}

A major cause of road deterioration is excessive water in the subbase of the highway combined with large traffic volumes and heavy loads. To decrease the road deterioration and extend the effective life of a highway, any excess water in a subbase needs to be removed. Therefore, proper drainage of the subbase has become a major concern in the design and rehabilitation of highways. The U.S. Geological Survey (USGS), in cooperation with the Ohio Department of Transportation (ODOT), evaluated discharge characteristics of four selected subbase drainage systems that consist of shallow longitudinal trenches with geocomposite drain materials (edge drains) that underlie the joint between the shoulder and the traffic lane. In Ohio, edge drains commonly consist of a 10-in.-wide longitudinal trench, backfilled with pea gravel, along the edge of the traffic lane. At the bottom of the trench is a 4-in.-diameter perforated drain pipe to channel water to outlet pipes. The edge drains function as sumps to intercept the lateral flow of excess water from subbases and infiltration from joints and surface cracks. Because of the low permeability of the subgrade materials under the shoulder, which sometimes functions as a hydraulic barrier and impedes the drainage of the subbases, outlet pipes are used to channel the water away from the subbases through the shoulder. 
Three geocomposite edge drains and a conventional edge drain were installed by ODOT according to the manufacturers' specifications. The four edge drain systems were connected to outlet pipes which routed the excess water of the subbase through specially designed tipping-bucket gages to monitor the discharge characteristics through the drainage systems.

\section{Purpose and Scope}

This report documents the discharge characteristics of four highway drain materials (edge drains) under nearly equal geological and environmental conditions. The four edge drains were installed under State Route 16 approximately $1.0 \mathrm{mi}$ southeast of Granville, Ohio (fig. 1). Discharge from the four edge drains was monitored from April 1991 through November 1993. The discharge characteristics presented from the four edge drains consist of maximum discharges, discharge volumes, and lag times of specific discharge characteristics during selected rainfall events. ${ }^{1}$

\section{Previous Studies}

In a previous study (Jeffcoat and others, 1992), flow patterns underneath the highway surface were analyzed to determine how excess water escaped the subbases. On several occasions, piezometric water levels were above the roadway surface, which indicates that excess water was not escaping from the subbases very effectively. The study team concluded that edge drains and permeable subbases are critical aspects for the effective channeling of water away from the highway subbases. Although the previous study determined that effective edge drains extend the life of highways, it did not investigate the discharge characteristics of different shapes of geocomposite edge drains under similar geological and environmental conditions. Instrumentation was developed during the previous study by Jeffcoat and others (1992) to measure the discharge from the outlet pipes of the edge drains as well as the concurrent rainfall over the area.

\footnotetext{
${ }^{1}$ An event is defined as the occurrence of rain with a resultant runoff discharge.
}

Another previous study investigated the discharge characteristics of a post edge drain and a conventional edge drain (Hinshaw, 1988), but the results of this study were inconclusive.

\section{DATA COLLECTION}

Discharge data from the edge drains were recorded by electronic data loggers in the field and retrieved by telemetry or with a laptop computer. Maximum discharge, discharge volumes, and lag times for selected discharge characteristics were computed for selected events recorded from April 1991 through November 1993. Data-collection periods were generally from mid-April to the beginning of December to protect the instrumentation from freezing during the cold winter months.

\section{Edge Drain Description and Installation}

The three geocomposite edge drain products were chosen by ODOT to provide a representative sample of the designs on the market (fig. 2). The "conventional" edge drain is the typical 4-in.-diameter perforated polyethylene drain pipe in a 10-in.-wide trench backfilled with pea gravel used throughout Ohio for longitudinal edge drains. The "post" edge drain is constructed from a polyethylene core consisting of many hollow posts connected to a perforated mat and surrounded by a geotextile fabric ${ }^{2}$. The "oblong-pipe" edge drain is a polyethylene perforated oblong pipe surrounded by a geotextile fabric. The "cusp" edge drain is a polyethylene perforated mat with many raised pedestal-like cusps surrounded by a geotextile fabric.

The study site was selected because of the elevated roadway relative to the adjacent land surface and constant, gently sloping road grade. The elevated highway surface and the shallow depth of the edge drains (within 36 in. from the highway surface) minimized the potential effects of ground water. Each edge drain was hydraulically isolated from the other by short independent edge drains installed directly upgradient from each edge drain.

\footnotetext{
${ }^{2}$ A geotextile fabric is a manufactured material used to filter out the fine materials while allowing water to escape the subbase.
} 

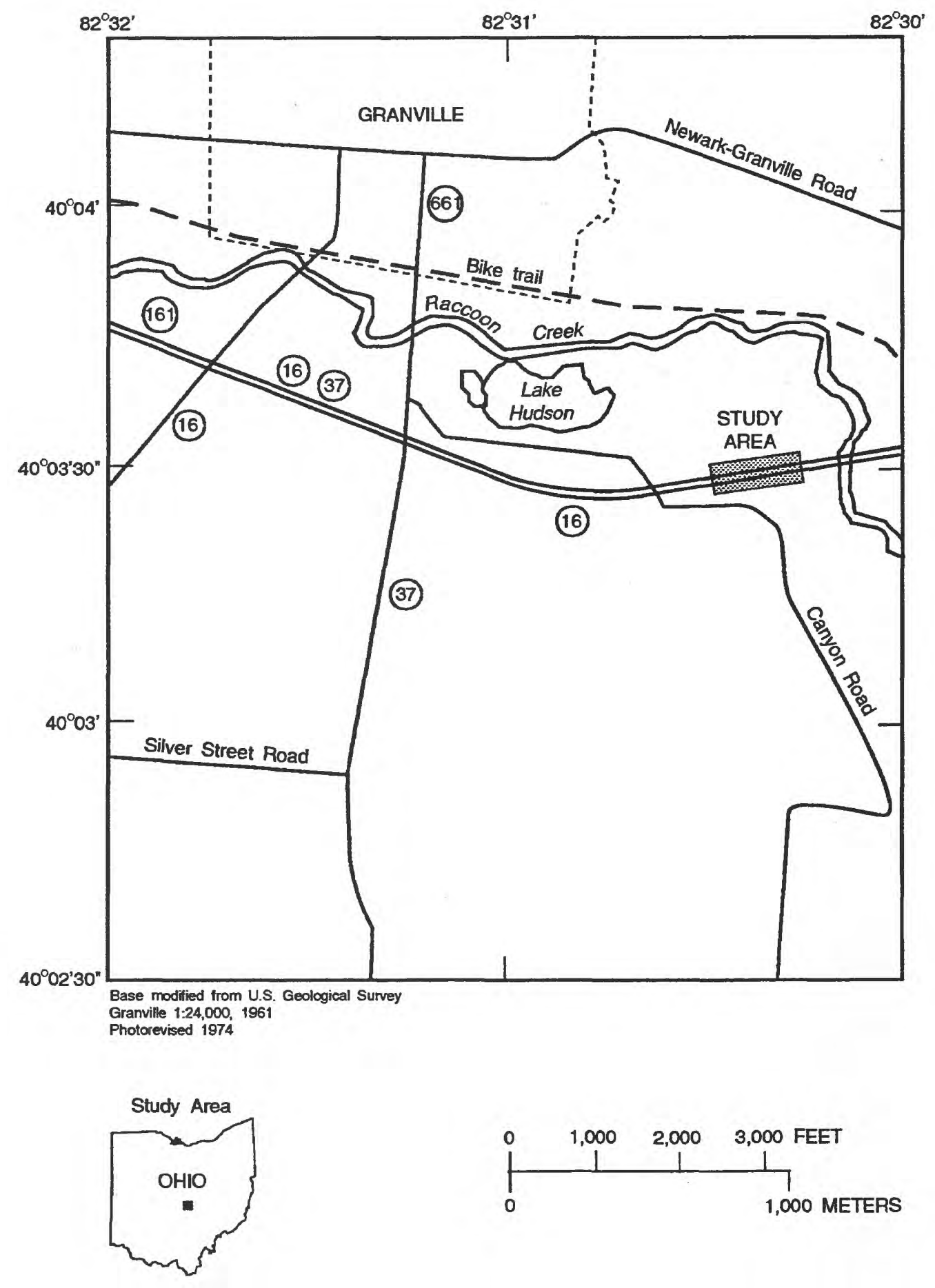

Figure 1. Location of edge drain study site at Granville, Ohio. 


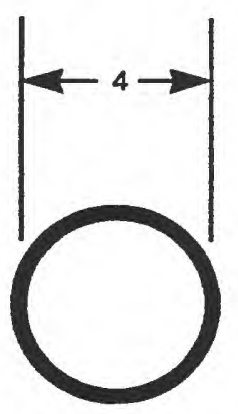

CONVENTIONAL

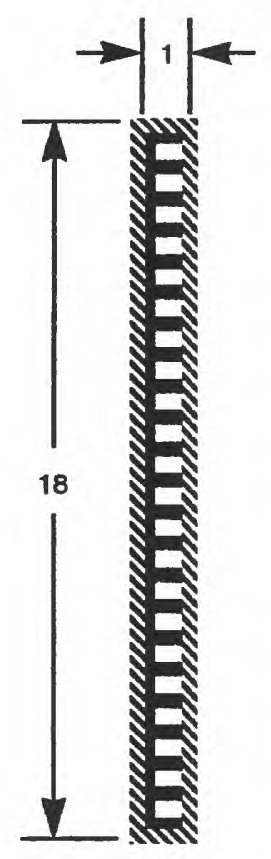

POST

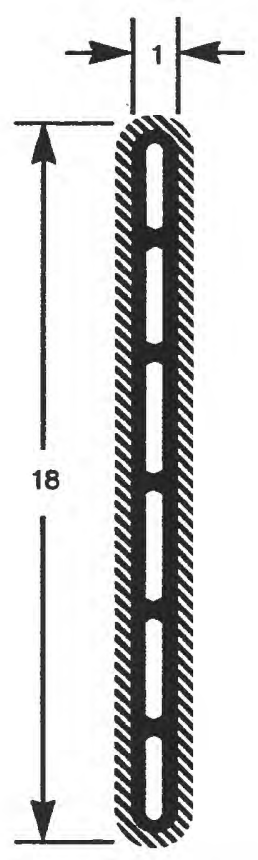

OBLONG PIPE

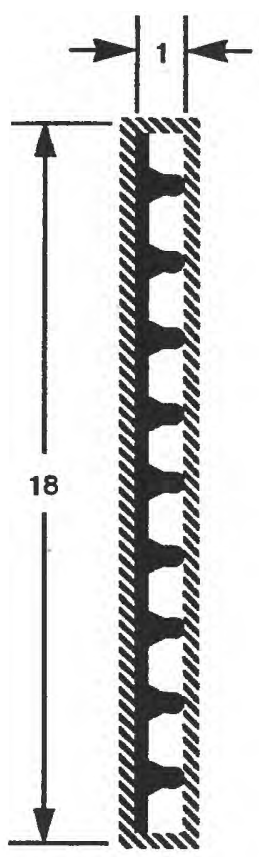

EXPLANATION

POLYETHYLENE CORE

GEOTEXTILE FILTER FABRIC

POLYETHYLENE PERFORATED PIPE

Figure 2. Cross-sectional views and construction characteristics of edge drains used in this investigation. (All dimensions are in inches.) 
All four edge drains were installed according to the manufacturer's specifications. Each edge drain is approximately $495 \mathrm{ft}$ long with observation ports in the middle and at each end of the edge drains. ODOT observed the amount of siltation in the edge drains through these observation ports in the highway surface. A schematic of the edge drain site is shown in figure 3. Cross-sectional views of the edge drain installations from the gage to the centerline of the eastbound lane of State Route 16 are shown in figure 4.

After installation of the edge drains, a cut approximately $1 / 8$-in. wide and $495 \mathrm{ft}$ long was sawn in the asphalt concrete overlay directly over the joint between the traffic lane and the shoulder for each edge drain. The cut, sawn into the top of the backfill directly above each edge drain, was intended to simulate the reflective cracks which usually develop in the pavement overlays. (Reflective cracks are cracks in the asphalt pavement that correspond to the existing joints in the portland cement concrete base.) In later stages of this project, the sawn cut partially filled with silt and sand-sized particles of road dust, but it still allowed water to infiltrate to the edge drains. Several reflective cracks developed in the highway surface in later stages of this project. The reflective cracks and the sawn cut increased the infiltration rate of water into the highway subbases.

\section{Instrumentation}

The outlet pipe for each edge drain was routed to an instrument shelter equipped with a dual tipping-bucket gage and a data logger (fig. 5). The design of the instrument shelters and tippingbucket gages was the same as that used in the study by Jeffcoat and others (1992). The tipping-bucket gages collect and record discharge from the edge drain outlet pipes. One instrument shelter was equipped with a tipping-bucket gage and recorder to collect and measure rainfall. (Rainfall was measured at only one shelter because of the close proximity of the four edge drains.) Bucket tips were tallied and recorded in 5-minute increments on the electronic data loggers.

The tipping buckets used to measure edge drain discharge were calibrated at a rate of one tip for each $0.076 \mathrm{ft}^{3}$ of water. Flows from the outlet pipes that exceed the capacity of the orifice for the tipping bucket flowed over a weir. The rate of flow over the weir was calibrated to the frequency of the bucket tips to eliminate the need for weir-head measurements; thus, total discharge from the edge drains (through the tipping bucket and over the weir) can be determined from the recorded frequency of tips. The tipping bucket used to measure the rainfall was calibrated to a rate of one bucket tip for every $0.05 \mathrm{in}$. of rainfall. Tipping-bucket gages were initially calibrated at the USGS's Gulf Coast Hydroscience Center at the National Space Technology Laboratories in Mississippi. The edge drain tipping buckets were volumetrically calibrated in the field at the beginning of each datacollection period.

\section{Factors Affecting Accuracy of Data}

Although the sawn cut in the pavement above each edge drain filled with particles, this filling was assumed to have affected all four edge drains equally. Temperature also affected the sawn cut by varying the width of the cut, but this variation also was assumed to have affected all four edge drains equally. Several reflective cracks that formed in the roadway asphalt increased the infiltration rate of water into the subbases. The amount of reflective cracks and the infiltration rates from these cracks were unknown, therefore, the amount of infiltration from the reflective cracks was assumed to be equal for all four edge drains.

An assumption made at the beginning of this study was that all edge drains were installed under equal geologic and environmental conditions; however, a hole in the embankment was discovered approximately $41 \mathrm{ft}$ from the upper observation port of the cusp edge drain (fig. 3). Water collecting in this upper part of the edge drain may have escaped laterally instead of flowing out the outlet pipe, eroded the subbase under the shoulder, and formed this hole near the edge of the highway. On several occasions during inspections by ODOT there was standing water in the upstream observation port of this edge drain. The most probable cause is blockage by a kink in the edge drain that might have occurred during installation. This pos- 


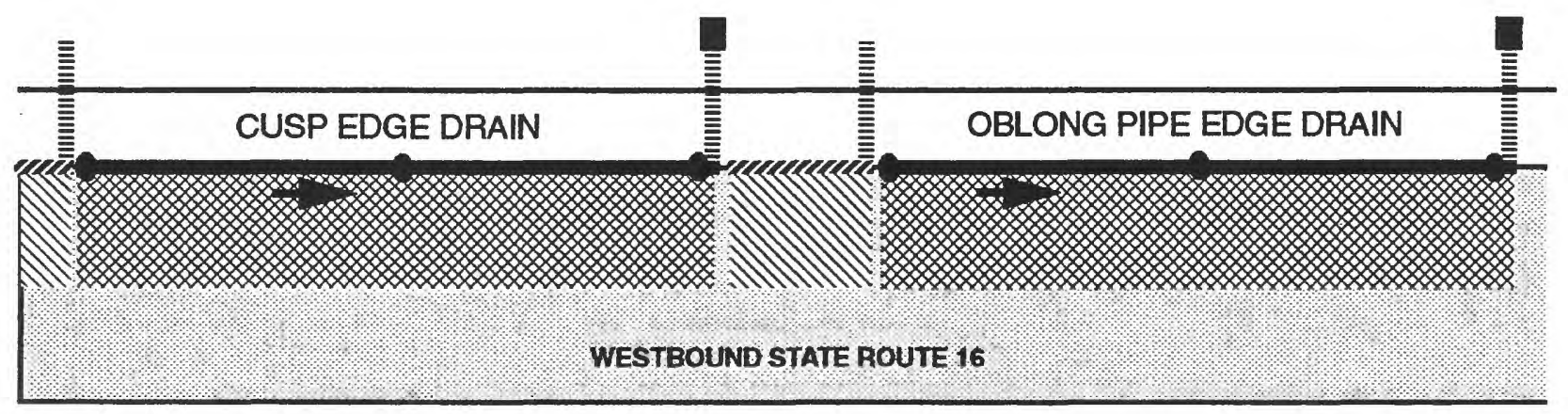

MEDIAN

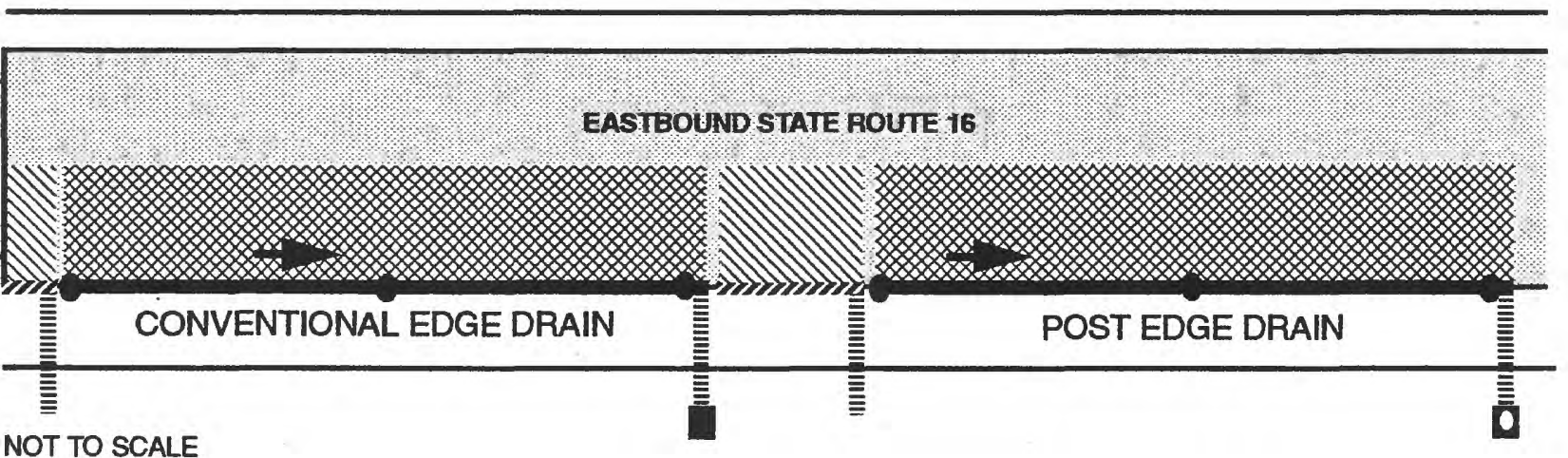

NOT TO SCALE

\section{EXPLANATION}

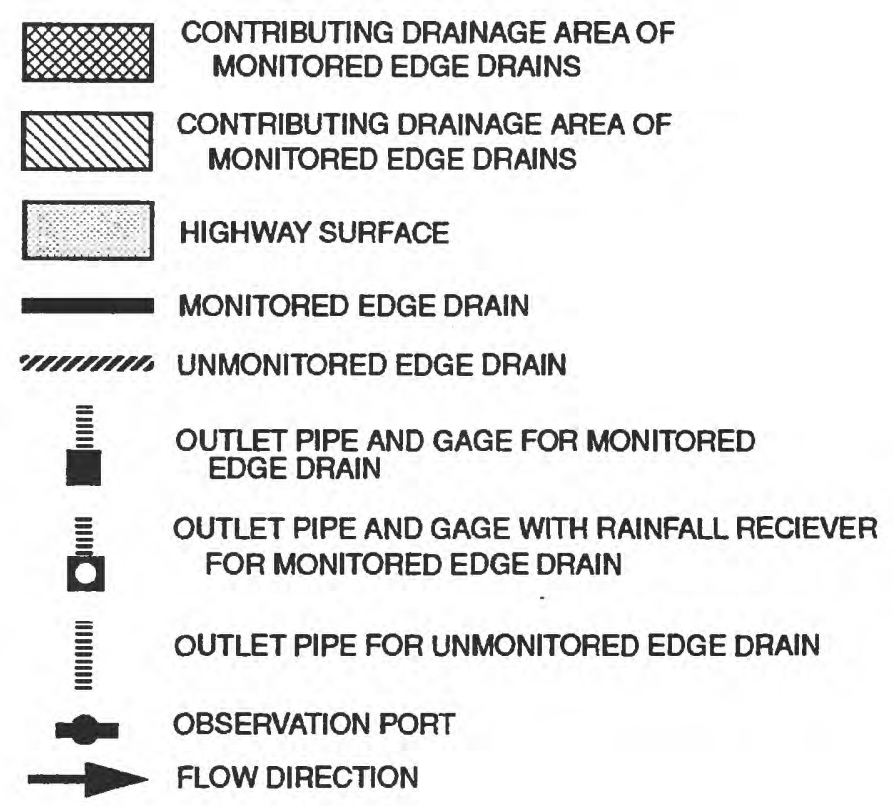

Figure 3. Plan view of edge drain study site at State Route 16, Granville, Ohio. 


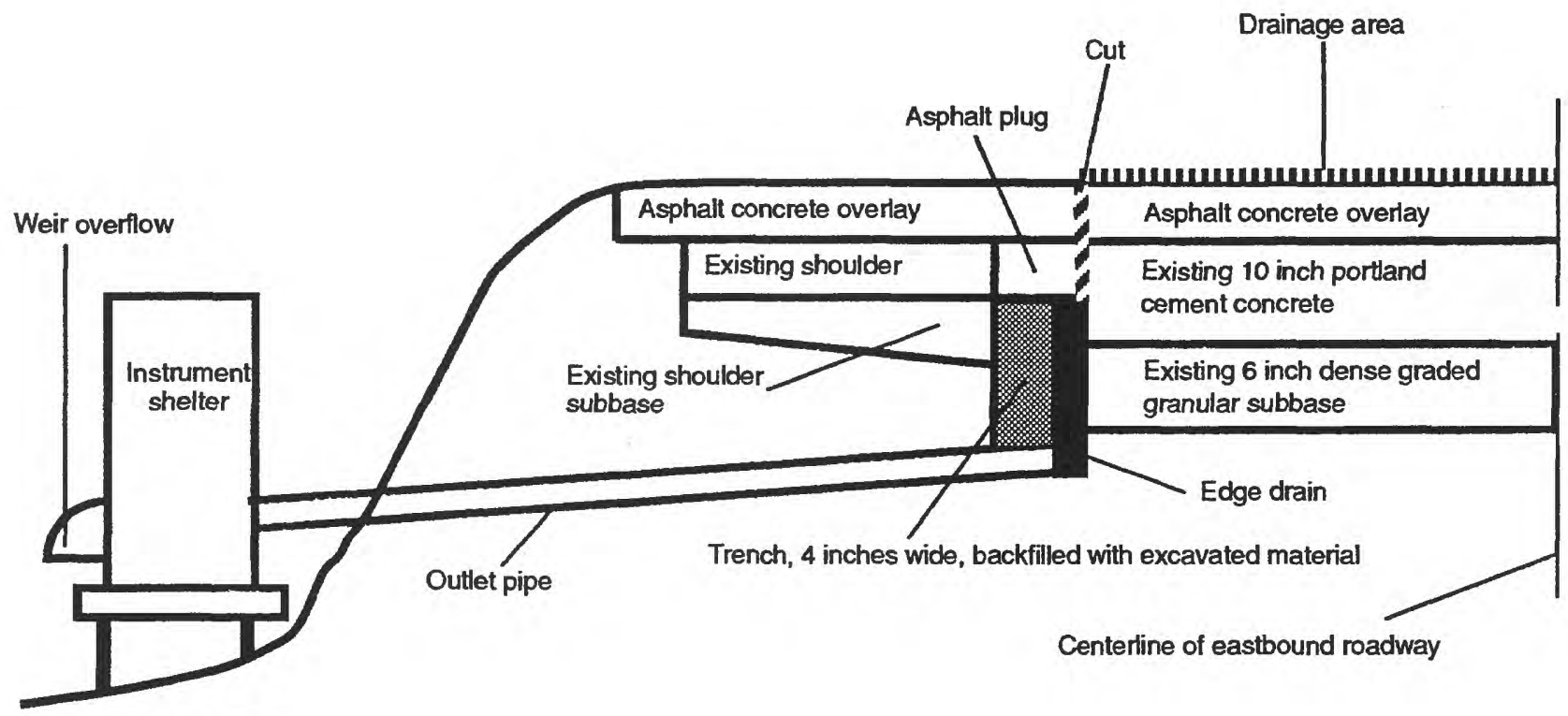

Not to scale

\section{GEOCOMPOSITE EDGE DRAIN}

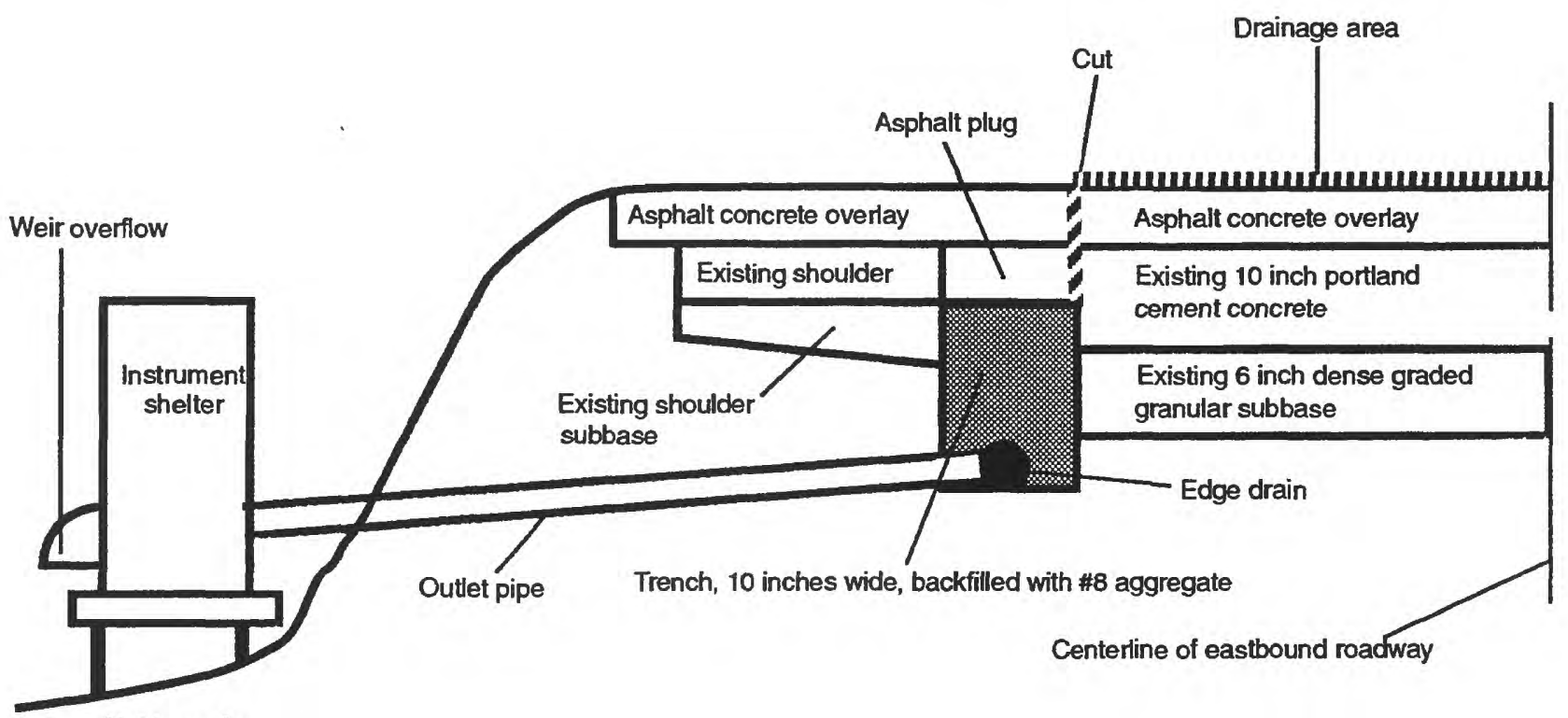

Not to scale

\section{CONVENTIONAL EDGE DRAIN}

Figure 4. Cross section of eastbound lane of State Route 16 at edge drain study site. 
EXPLANATION

1 RAINFALL RECEIVER

2 SHELTER HOUSE

3 RAINWATER TUBE

4 RAINFALL TIPPING BUCKET

5 EDGE DRAIN OUTLET PIPE

6 ORIFICE FOR RUNOFF

7 DISCHARGE TIPPING BUCKET

8 OVERFLOW WEIR

9 SUPPORT BRACKET

10 BUMPER STOP

11 MAGNETIC PROXIMITY SWITCH

12 DATA LOGGER
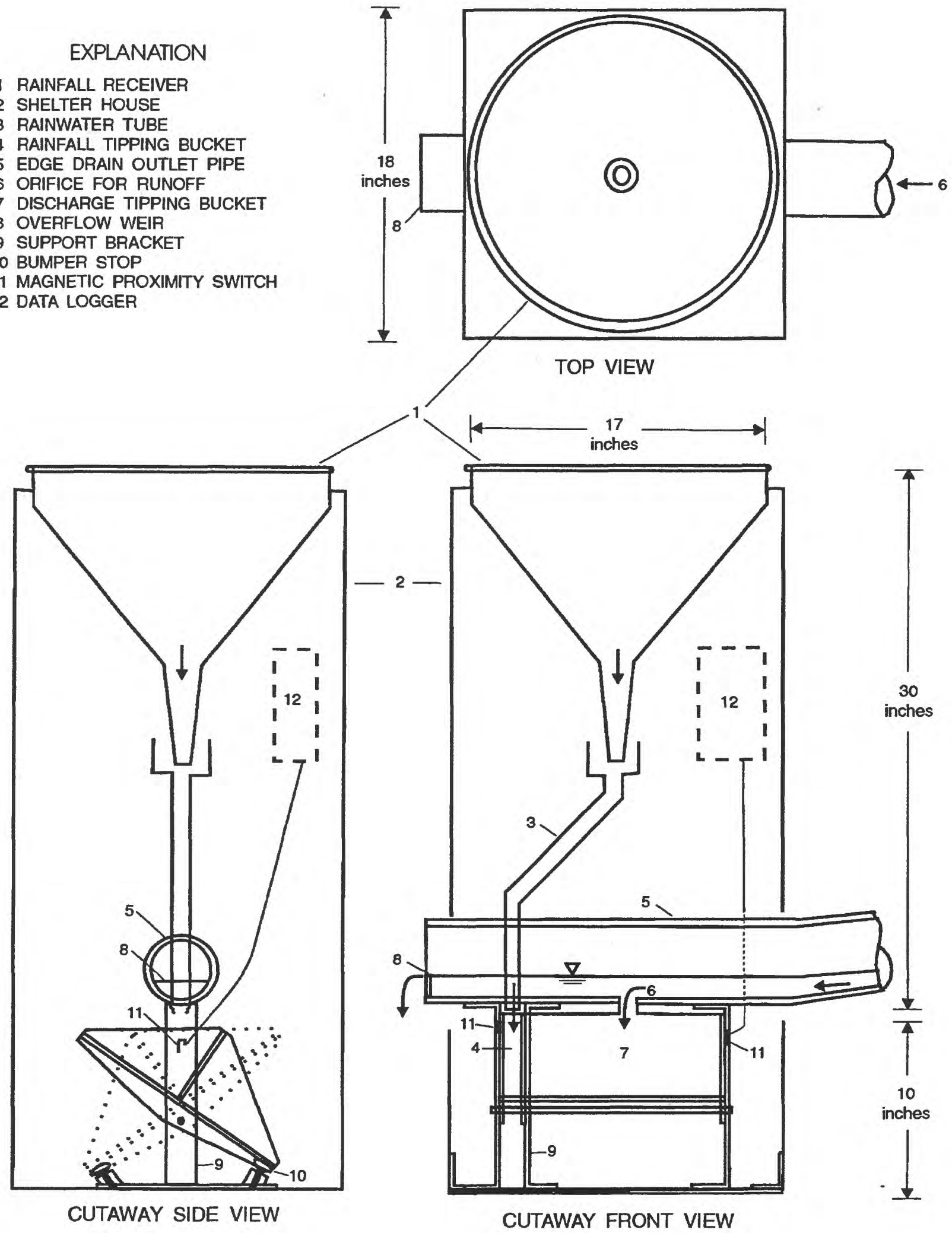

Figure 5. Design of dual tipping-bucket gage (modified from Jeffcoat and others, 1992, fig. 6). 
sibility, however, can only be confirmed when the edge drain is repaired. Because of this suspected blockage or kink, the effective length of the cusp edge drain is reduced to approximately $454 \mathrm{ft}$. The maximum discharge, discharge volume, and lag times from the cusp edge drain were affected by an unknown amount.

Another possible problem that may have affected the data is a sag in the conventional edge drain about $15 \mathrm{ft}$ from the lowest observation port. The low point of the perforated pipe in this sag appeared to be full of water but was not obstructed during an inspection. Depending on the event and the conditions before the event, this sag could have affected some of the discharge characteristics. It is not known whether the sag drained during dry periods, so the amount of the effect could have been recurring. If the sag did not drain during dry periods or become obstructed, then the effects were minimal for all events. If the sag drained during dry periods, however, the sag would affect the discharge by an unknown amount for each rainfall event. The water would initially fill the sag and then flow as if the sag did not exist. Large and small discharge events would be affected by this sag, however, the percentage of error for the larger events would be less.

\section{DISCHARGE CHARACTERISTICS OF HIGHWAY DRAINAGE SYSTEMS}

Discharge characteristics presented for the four edge drains were the maximum discharges measured in cubic feet per hour, discharge volumes in cubic feet, and lag times in minutes between several event characteristics for each edge drain from selected events. In general, the conventional edge drain was the most closely matched by the oblongpipe edge drain. Most of the event characteristics for the conventional and oblong-pipe edge drain were similar for every event. The events ranged in total rainfall from less than 0.05 in. to approximately $2.10 \mathrm{in}$. and are assumed to have covered the entire drainage area uniformly for each edge drain. (The drainage area of each edge drain as shown in figure 3 was surveyed and computed as the area enclosed by a rectangle from the sawn cut to the crown or center line of the highway surface.)
Event durations ranged from about 1 hour to 20 hours. Only data for those rainfall events during which all gages were functioning properly and accurately with respect to the characteristic being compared were used in this analysis. For several events, a small discharge was recorded but no bucket tips registered for the rainfall tippingbucket gage; total rainfall was less than 0.05 in. for these events. Although lag times could not be computed for these events, maximum discharges and volumes for these events were still used in the analysis.

Five-minute-increment rainfall totals for the events ranged from less than 0.05 in. to approximately $0.30 \mathrm{in}$. The long-duration, low-intensity rainfall events produced some of the highest maximum discharges and volumes. For most of the events with high maximum discharges and volumes, the intensity remained at 0.05 or $0.10 \mathrm{in}$. (one or two tips) per 5-minute interval for several consecutive intervals. For the high-intensity rainfall events, 0.15 to 0.30 in. (three to six tips) per 5-minute interval, the increase in the rate of discharge from the edge drains was not significant. The low-intensity events allowed more water to infiltrate into the subbase than the high-intensity events. For the high-intensity events, most of the water probably flowed over the sawn cut and over the shoulder, bypassing the edge drains.

\section{Maximum Discharge}

The maximum discharges of the four edge drains were presented only if all four edge drain gages were operating properly during an event. The comparison of the maximum discharges for the edge drains was based on 72 events. Several events consisted of multiple discharge peaks; in such cases, only the maximum discharges for each of the events were used in the comparison. During some of the events, for example, the maximum discharges occurred shortly after the onset of the rain. As additional rain fell, second peaks occurred, but they were usually not as high as the initial peaks. If, however, the discharges during an event from all the edge drains decreased to about $0.73 \mathrm{ft}^{3} / \mathrm{hr}$ (one tip in 5 minutes) and then peaked again, the 
discharge peaks were separated and analyzed individually. Maximum-discharge data for each edge drain are summarized in figure 6 and table 1.

Table 1. Statistics for maximum discharges for each edge drain for 72 events, 1991-93 for State Route 16 near Granville, Ohio

[All units are in cubic feet per hour and rounded to 3 significant digits; $\mathrm{CV}$ is the coefficient of variation; IQR is the interquartile range; Range is the maximum value minus the minimum value; Midrange is the value midway between the maximum and minimum values]

\begin{tabular}{lcccc}
\hline & \multicolumn{4}{c}{ Edge drain type } \\
\cline { 2 - 5 } \multicolumn{1}{c}{ Statistic } & $\begin{array}{c}\text { Conven- } \\
\text { tional }\end{array}$ & Post & $\begin{array}{c}\text { Oblong } \\
\text { pipe }\end{array}$ & Cusp' \\
\hline Mean & 8.00 & 3.38 & 7.99 & 3.36 \\
Standard & & & & \\
$\quad$ deviation & 6.03 & 3.31 & 5.81 & 2.21 \\
CV & .755 & .980 & .726 & .657 \\
Minimum & .730 & .730 & .730 & .730 \\
Maximum & 31.9 & 18.1 & 29.4 & 8.94 \\
Median & 6.20 & 2.55 & 7.11 & 2.55 \\
IQR & 6.38 & 3.65 & 4.56 & 3.65 \\
25th percentile & 4.38 & .730 & 4.38 & 1.64 \\
75th percentile & 10.8 & 4.38 & 8.94 & 5.29 \\
Range & 31.1 & 17.3 & 28.7 & 8.21 \\
Midrange & 16.3 & 9.40 & 15.1 & 4.84 \\
& & & & \\
\hline
\end{tabular}

\footnotetext{
${ }^{1}$ All edge drains were installed under nearly equal geological and environmental conditions; however, a hole in the embankment was discovered approximately 41 feet from the upper observation port of the cusp edge drain (fig. 3). Some water flowing from the edge drain may have escaped laterally instead of flowing out the outlet pipe and through the gage.
}

The mean maximum discharges of the conventional and oblong-pipe edge drains were approximately equal, and both were higher than the means of the post and cusp edge drains. For almost every event, the maximum discharges of the conventional and oblong-pipe edge drains were either equal to or higher than those from the post and cusp edge drains. The smallest maximum discharge for all the edge drains was $0.73 \mathrm{ft}^{3} / \mathrm{hr}$. A few of the large events produced maximum discharges from the conventional and oblong-pipe edge drains that were larger than the capacity of the orifice of the tipping-bucket gages and flowed over the weir. The post and cusp edge drains did not produce enough flow to overtop the weir during any of the events used in the analysis. The largest maximum discharges ranged from $8.94 \mathrm{ft}^{3} / \mathrm{hr}$ for the cusp edge drain to $31.9 \mathrm{ft}^{3} / \mathrm{hr}$ for the conventional edge drain.
The mean maximum discharges for all the edge drains were computed to give a general idea of the discharge characteristics of the four edge drains. The standard deviation and coefficient of variation also were computed to measure the variability of the four edge drain data sets. The variability of the maximum discharge for each of the edge drains is a function of the amount of rain falling over the drainage areas and the effectiveness of the edge drains in channeling the water out of the subbase. Although the standard deviations relative to the means for the edge drains are nearly equal, the maximum discharges were usually much greater for the conventional and oblong-pipe edge drains than for the post and cusp edge drains.

Although the mean maximum discharge for the conventional edge drain was the highest among all the edge drains, the median maximum discharge for the oblong-pipe edge drain was the highest median among the four edge drains. The medians also were used for comparison because of the variability of the data sets and some extremely high discharges from the conventional and oblong-pipe edge drains. Extreme values do not affect the medians as much as they will affect the means of the maximum discharges. The median maximum discharges for the post and cusp edge drains were much smaller than the median maximum discharges for the conventional and the oblong-pipe edge drains. Median maximum discharges for the conventional and oblong-pipe edge drains were at least two times the median maximum discharges for the post and cusp edge drains.

\section{Volumes}

The volumes were computed from the discharge data for all four edge drains and presented for 55 events. The volumes were computed as the summation of all discharges from the beginning of an event to the end of the event. The mean and median volumes of the oblong-pipe edge drain were the largest among the four edge drains. The oblong-pipe edge drain also had the lowest coefficient of variation among the four edge drain data sets. The volumes of all four edge drains ranged from $0.06 \mathrm{ft}^{3}$ for the post edge drain to $67.6 \mathrm{ft}^{3}$ for the conventional edge drain. Discharge vol- 


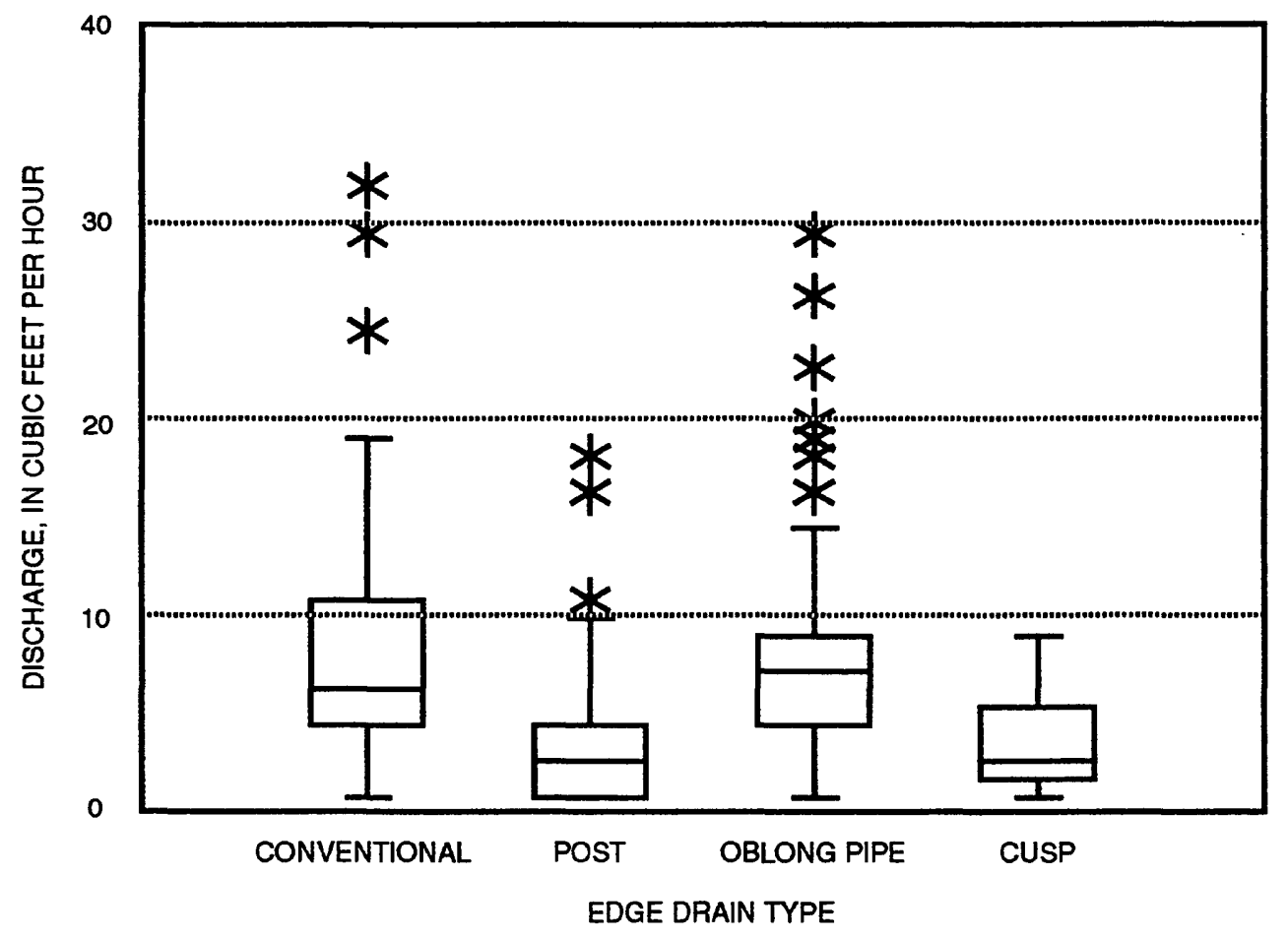

EXPLANATION

* Data point is greater than

1.5 times the interquartile

range from the box.

7

Largest data point less

than or equal to the upper

quartile plus 1.5 times the

interquartile range.

$75^{\text {th }}$ Percentile

Median

$25^{\text {th }}$ Percentile

Smallest data point

greater than or equal to

the lower quartile minus

1.5 times the interquartile

range.

Figure 6. Distribution of maximum discharges for each edge drain for 72 events, 1991-93 for State Route 16 near Granville, Ohio. (All edge drains were installed under nearly equal geological and environmental conditions; however, a hole in the embankment was discovered approximately 41 feet from the upper observation port of the cusp edge drain (fig. 3). Some water flowing from the edge drain may have escaped laterally instead of flowing out the outlet pipe and through the gage.) 
ume data for each edge drain are summarized in figure 7 and table 2 .

Table 2. Statistics for volumes for each edge drain for 55 events, 1991-93 for State Route 16 near Granville, Ohio

[All units are in cubic feet and rounded to 3 significant digits; CV is the coefficient of variation; IQR is the interquartile range; Range is the maximum value minus the minimum value; Midrange is the value midway between the maximum and minimum values]

\begin{tabular}{lcccc}
\hline & \multicolumn{4}{c}{ Edge drain type } \\
\cline { 2 - 5 } \multicolumn{1}{c}{ Statistic } & $\begin{array}{c}\text { Conven- } \\
\text { tional }\end{array}$ & Post & $\begin{array}{c}\text { Oblong } \\
\text { pipe }\end{array}$ & Cusp' \\
\hline Mean & 16.1 & 5.75 & 18.9 & 12.1 \\
Standard & & & & \\
$\quad$ deviation & 15.5 & 8.65 & 13.4 & 11.5 \\
CV & .963 & 1.51 & .708 & .950 \\
Minimum & .620 & .060 & 1.89 & .120 \\
Maximum & 67.6 & 38.6 & 63.0 & 57.6 \\
Median & 11.2 & 2.81 & 15.1 & 8.53 \\
IQR & 16.7 & 7.10 & 18.4 & 12.2 \\
25th percentile & 5.53 & .67 & 7.63 & 4.15 \\
75th percentile & 22.2 & 7.77 & 26.0 & 16.4 \\
Range & 67.0 & 38.5 & 61.1 & 57.5 \\
Midrange & 34.1 & 19.3 & 32.4 & 28.9 \\
\hline
\end{tabular}

${ }^{1}$ All edge drains were installed under nearty equal geological and environmental conditions; however, a hole in the embankment was discovered approximately $\mathbf{4 1}$ feet from the upper observation port of the cusp edge drain (fig. 3). Some water flowing from the edge drain may have escaped laterally instead of flowing out the outlet pipe and through the gage.

Runoff volumes for each edge drain were also presented as a ratio of the total rain falling over the contributing drainage areas. The rainfall volumes were computed as rainfall multiplied by the contributing drainage area for each edge drain. Of course, not all the water falling onto the highway surface infiltrated into the edge drains; most of the water flowed over the sawn cut, across the shoulder surface and down the embankment, bypassing the edge drains altogether. The highest percentage of discharge volume to rainfall volume was 64.0 percent for the oblong-pipe edge drain. The means and medians for this characteristic were all less than 20 percent for all four edge drains. The ratio of discharge volumes to rainfall volumes is summarized in figure 8 and in table 3 to highlight the relation of the water exiting the edge drain to the amount of water entering the systems.
Table 3. Statistics for discharge volumes as a percentage of rainfall volume for each edge drain for 55 events, 1991-93 for State Route 16 near Granville, Ohio

[All units are dimensionless and rounded to 3 significant digits; $\mathrm{CV}$ is the coefficient of variation; IQR is the interquartile range; Range is the maximum value minus the minimum value; Midrange is the value midway between the maximum and minimum values]

\begin{tabular}{lcccc}
\hline & \multicolumn{4}{c}{ Edge drain type } \\
\cline { 2 - 5 } \multicolumn{1}{c}{ Statistic } & $\begin{array}{c}\text { Conven- } \\
\text { tional }\end{array}$ & Post & $\begin{array}{c}\text { Oblong } \\
\text { pipe }\end{array}$ & Cusp' \\
\hline Mean & 15.0 & 3.49 & 19.0 & 11.1 \\
Standard & & & & \\
$\quad$ deviation & 11.6 & 2.98 & 12.2 & 8.84 \\
CV & .772 & .855 & .641 & .794 \\
Minimum & 1.46 & .210 & 3.18 & .430 \\
Maximum & 51.7 & 12.3 & 64.0 & 44.0 \\
Median & 10.8 & 2.53 & 17.5 & 8.84 \\
IQR & 15.5 & 3.97 & 12.2 & 11.8 \\
25th percentile & 6.93 & 1.36 & 10.3 & 4.43 \\
75th percentile & 22.4 & 5.33 & 22.5 & 16.2 \\
Range & 50.2 & 12.1 & 60.8 & 43.6 \\
Midrange & 26.6 & 6.26 & 33.6 & 22.2 \\
& & & & \\
\hline
\end{tabular}

\begin{abstract}
${ }^{1}$ All edge drains were installed under nearly equal geological and environmental conditions; however, a hole in the embankment was discovered approximately 41 feet from the upper observation port of the cusp edge drain (fig. 3). Some water flowing from the edge drain may have escaped laterally instead of flowing out the outlet pipe and through the gage.
\end{abstract}

Threshold-based volumes also were computed for the comparison of the four edge drains. A threshold-based volume is defined as the quantity of water from the beginning of the selected event to the time when the discharge falls below 20 percent of the maximum discharge of the hydrograph of each edge drain. The threshold for most of the small events occurred when the discharge for an interval equaled zero. The threshold-based volumes were computed to analyze the volumes of the edge drains without the long, flat recession discharge included in the hydrographs. The threshold-based volumes were smaller than the regular volumes for each edge drain, but the comparison of the threshold-based volumes was similar to the comparison of the regular volumes. Therefore, the results of the threshold-based volumes are not presented in this report. 


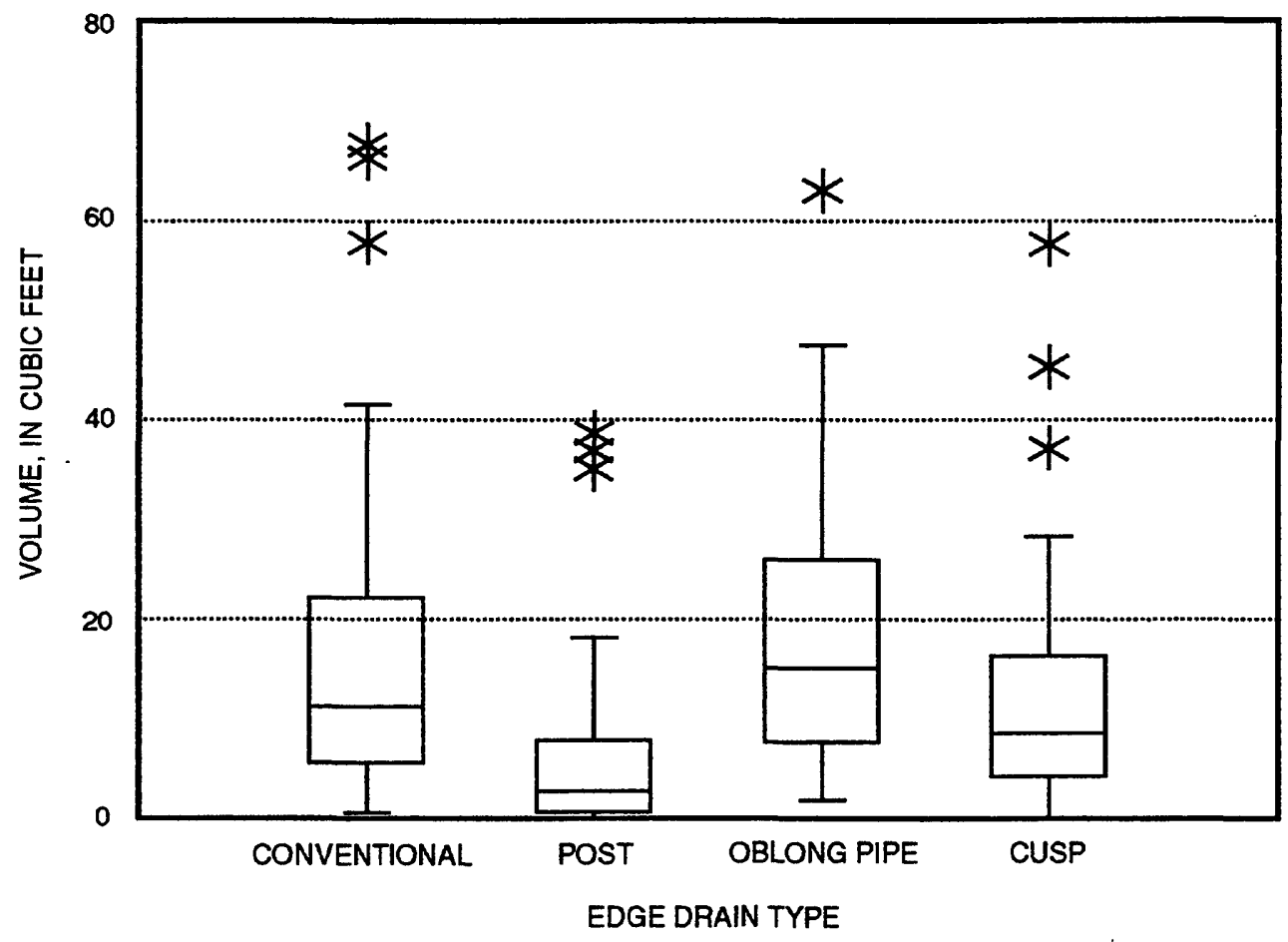

EXPLANATION

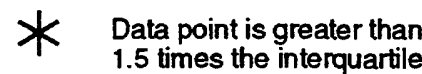
range from the box.

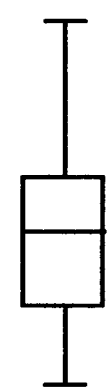

Largest data point less

than or equal to the upper

quartile plus 1.5 times the interquartile range.

$75^{\text {th }}$ Percentile

Median

$25^{\text {th }}$ Percentile

Smallest data point

greater than or equal to

the lower quartile minus

1.5 times the interquartile range.

Figure 7. Distribution of volumes for each edge drain for 55 events, 1991-93 for State Route 16 near Granville, Ohio. (All edge drains were installed under nearly equal geological and environmental conditions; however, a hole in the embankment was discovered approximately 41 feet from the upper observation port of the cusp edge drain (fig. 3). Some water flowing from the edge drain may have escaped laterally instead of flowing out the outlet pipe and through the gage.) 


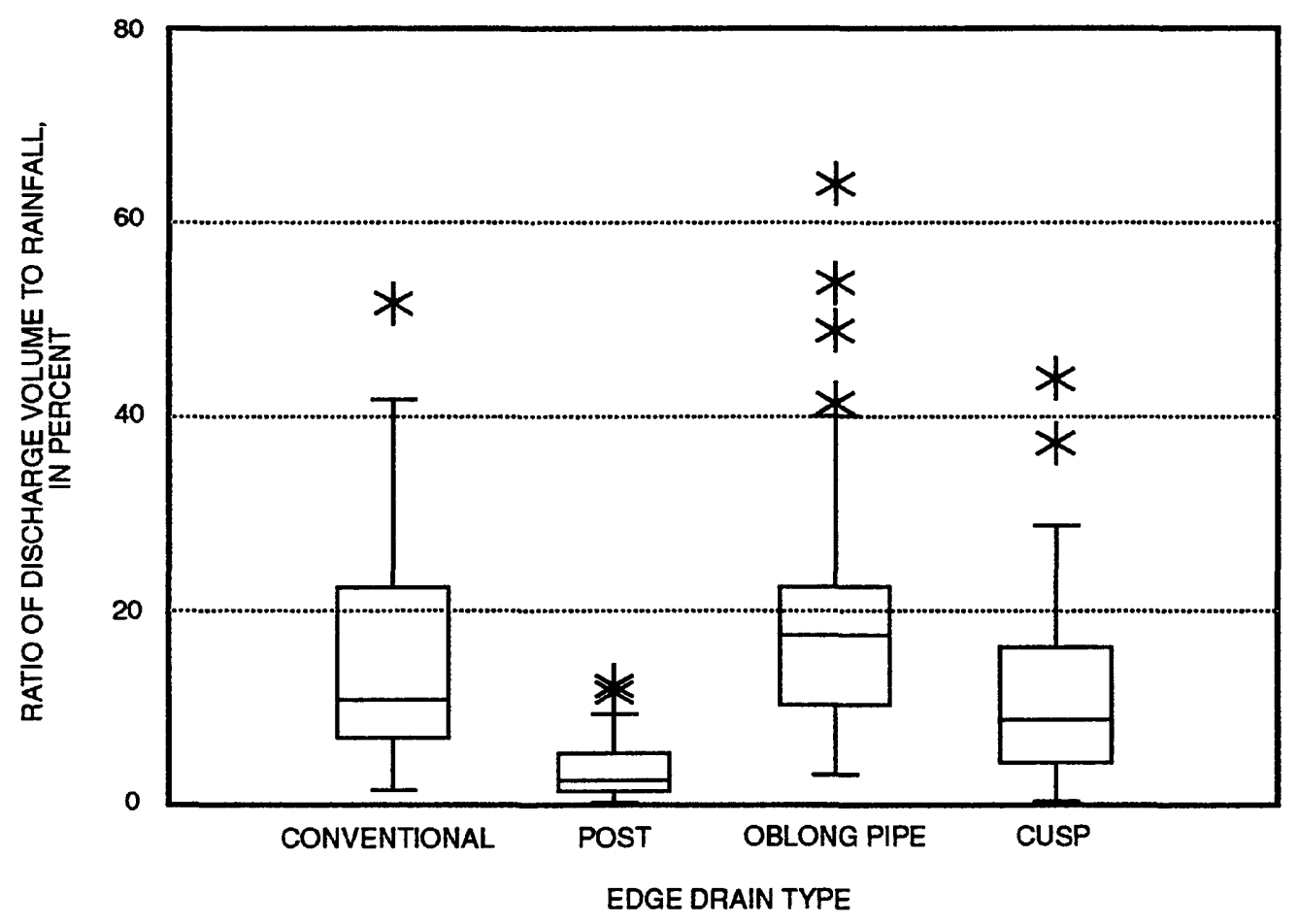

\title{
EXPLANATION
}

\author{
* Data point is greater than \\ 1.5 times the interquartile \\ range from the box. \\ T Largest data point less \\ than or equal to the upper \\ quartile plus 1.5 times the \\ interquartile range.

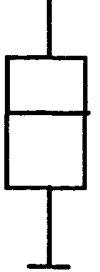 \\ $75^{\text {th }}$ Percentile \\ Median \\ $25^{\text {th }}$ Percentile \\ Smallest data point \\ greater than or equal to \\ the lower quartile minus \\ 1.5 times the interquartile \\ range.
}

Figure 8. Distribution of the ratios of discharge volumes to rainfall volumes for each edge drain for 55 events, 1991-93 for State Route 16 near Granville, Ohio. (All edge drains were installed under nearly equal geological and environmental conditions; however, a hole in the embankment was discovered approximately $\mathbf{4 1}$ feet from the upper observation port of the cusp edge drain (fig. 3). Some water flowing from the edge drain may escaped laterally instead of flowing out the outlet pipe and through the gage.) 


\section{Lag Times}

Events used to calculate lag times for this analysis were carefully selected on the assumption that all edge drain gages and the rainfall gage were functioning properly and that a clear beginning and ending of the event could be determined. Some event characteristics were avoided. In particular, multiple peaks, where the recession of the hydrograph falls below the threshold and then increases again during an event, were discarded unless the peaks could be analyzed separately. A total of 51 events were used for the analysis of lag times. The centroid of each discharge hydrograph and the centroid of each rainfall hyetograph were calculated for each event for all four edge drains. The threshold-based hydrograph centroids were also calculated for each edge drain. Lag times were computed for the following event characteristics:

(1) the time from the centroid of the rainfall hyetograph to the centroid of the discharge hydrograph for each edge drain, (2) the time from the centroid of the rainfall hyetograph to the centroid of the threshold-based discharge hydrograph for each edge drain, (3) the time from the rainfall onset to the maximum discharge for each edge drain,

(4) the time from the rainfall onset to the centroid of the discharge hydrograph for each edge drain, (5) the time from the rainfall onset to the thresholdbased centroid of the discharge hydrograph for each edge drain, (6) the time from each hydrograph rise to its own maximum peak discharge, and (7) the time from each hydrograph rise to its own threshold. The lag times for the seven different event characteristics are illustrated in figure 9.

Because of the similarity of the data sets, only the lag times between rainfall centroid and hydrograph centroid (number 1) and the rainfall onset and hydrograph maximum (number 3 ) are discussed in this report. Most of the other lag times produced similar results to the centroid to centroid lag time (number 1). The only exception to the similarity is the lag time between rainfall onset and maximum discharge (number 3 ). All the lag times were calculated to provide a detailed analysis of the event characteristics, but other than the two lag times presented, the additional lag time analyses do not contribute much additional information.
The existing conditions before each rainfallrunoff event were carefully examined. For many of the events, discharge registered on or before the same time interval as the rainfall. If the rainfall tipping bucket was empty and the discharge tipping bucket was nearly full, then the discharge bucket probably tipped on or before the interval in which the rain registered. Also, the sawn cut in the highway surface and the reflective cracks increased the infiltration rate of the water to the edge drains. For events in which discharge registered in the interval before the rainfall registered, the lag times were computed as if the discharge and the rainfall occurred in the same time interval.

The lag times between the rainfall centroid and the discharge hydrograph centroid (number 1) were similar for the conventional and oblongpipe edge drains. The post edge drain had the shortest mean lag time between the centroid of the rainfall hyetograph and the centroid of each edge drain hydrograph (table 4).

Table 4. Statistics for lag times between hydrograph centroid and hyetograph centroid for each edge drain for 51 events, 1991-93 for State Route 16 near Granville, Ohio

[All units are in minutes and rounded to 3 significant digits;

$C V$ is the coefficient of variation; IQR is the interquartile range; Range is the maximum value minus the minimum value; Midrange is the value midway between the maximum and minimum values]

\begin{tabular}{lcccc}
\hline \multicolumn{5}{c}{ Edge drain type } \\
\cline { 2 - 5 } \multicolumn{1}{c}{ Statistic } & $\begin{array}{c}\text { Conven- } \\
\text { tional }\end{array}$ & Post & $\begin{array}{c}\text { Oblong } \\
\text { plpe }\end{array}$ & Cusp' \\
\hline Mean & 63.9 & 37.4 & 78.3 & 119 \\
Standard & & & & \\
$\quad$ deviation & 33.2 & 20.8 & 31.0 & 54.9 \\
CV & .520 & .557 & .395 & .462 \\
Minimum & 5 & -10 & 30 & -5 \\
Maximum & 160 & 85 & 175 & 310 \\
Median & 65 & 40 & 70 & 105 \\
IQR & 50 & 25 & 40 & 65 \\
25th percentile & 35 & 30 & 55 & 85 \\
75th percentile & 85 & 55 & 95 & 150 \\
Range & 155 & 95 & 145 & 315 \\
Midrange & 82.5 & 37.5 & 102 & 152 \\
& & & & \\
\hline
\end{tabular}

\footnotetext{
${ }^{1}$ All edge drains were installed under nearly equal geological and environmental conditions; however, a hole in the embankment was discovered approximately 41 feet from the upper observation port of the cusp edge drain (fig. 3). Some water flowing from the edge drain may have escaped laterally instead of flowing out the outlet pipe and through the gage.
} 


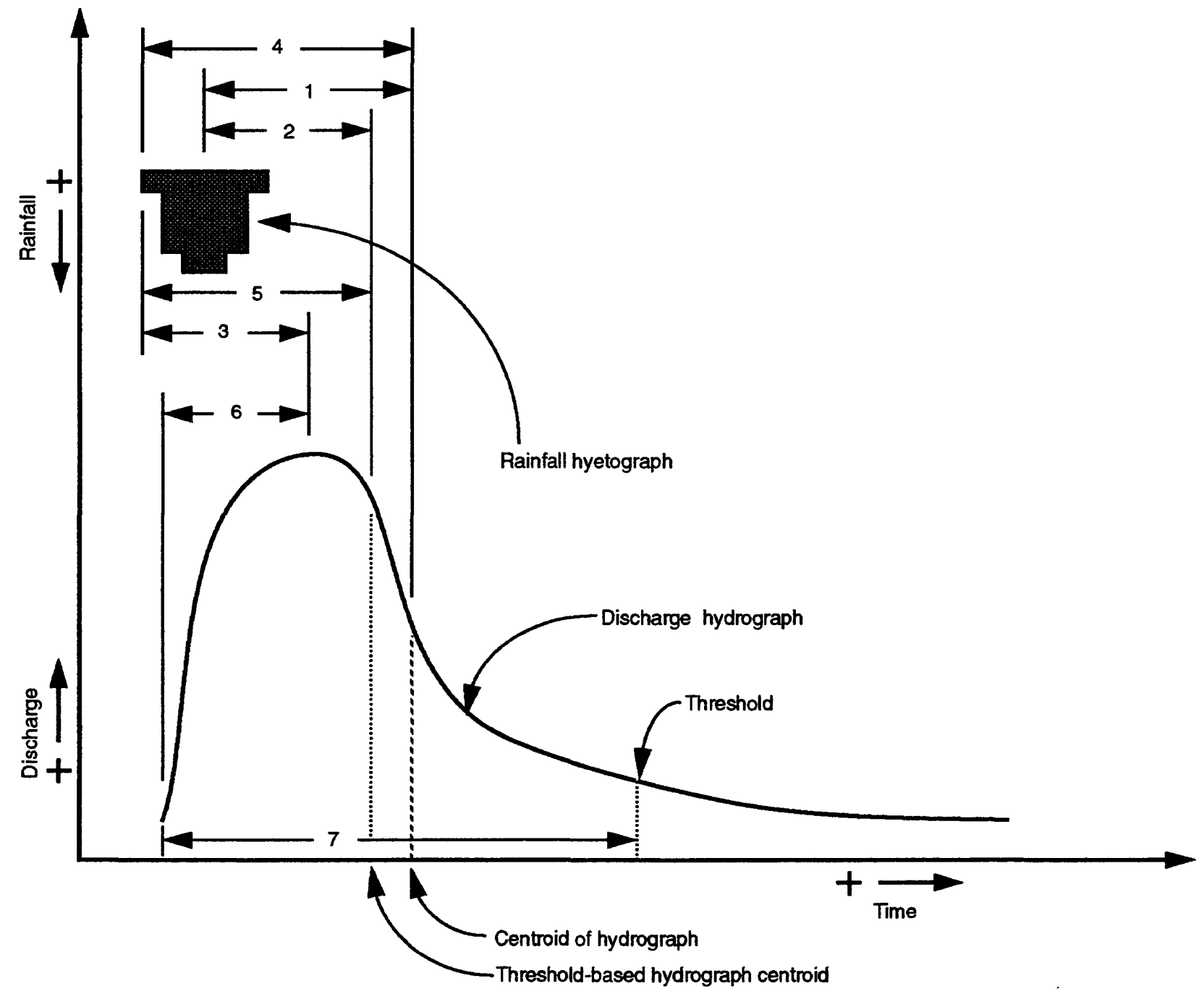

\section{EXPLANATION}

1 RAINFALL HYETOGRAPH CENTROID TO DISCHARGE HYDROGRAPH CENTROID

2 RAINFALL HYETOGRAPH CENTROID TO THRESHOD-BASED DISCHARGE HYDROGRAPH CENTOID

3 RAINFALL ONSET TO DISCHARGE HYDROGRAPH MAXIMUM

4 RAINFALL ONSET TO DISCHARGE HTDROGRAPH CENTROID

5 RAINFALL ONSET TO THRESHOLD-BASED DISCHARGE HYDROGRAPH CENTROID

6 DISCHARGE HYDROGRAPH RISE TO DISCHARGE HYDROGRAPH MAXIMUM

7 DISCHAGE HYDROGRAPH RISE TO DISCHARGE HYDROGRAPH THRESHOLD

Figure 9. Diagram showing calculated lag times. 


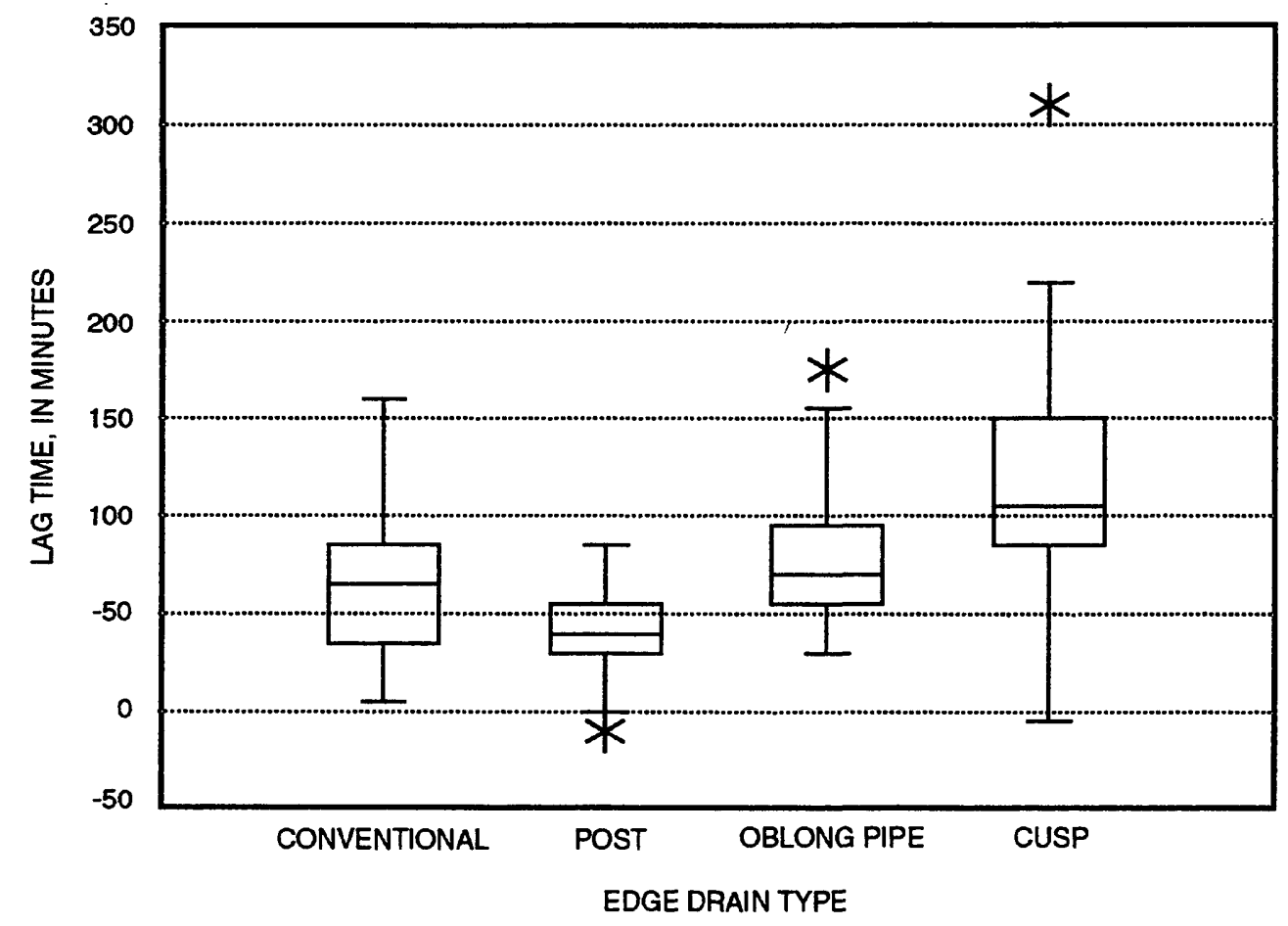

EXPLANATION

* Data point is greater than

1.5 times the interquartile range from the box.

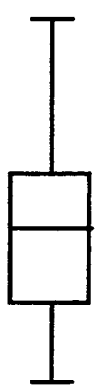

Largest data point less

than or equal to the upper

quartile plus 1.5 times the

interquartile range.

$75^{\text {th }}$ Percentile

Median

$25^{\text {th }}$ Percentile

Smallest data point

greater than or equal to

the lower quartile minus

1.5 times the interquartile

range.

Figure 10. Distribution of lag time between hydrograph centroid and hyetograph centroide for each edge drain for 51 events, 1991-93 for State Route 16 near Granville, Ohio. (All edge drains were installed under nearly equal geological and environmental conditions; however, a hole in the embankment was discovered approximately 41 feet from the upper observation port of the cusp edge drain (fig: 3). Some water flowing from the edge drain may have escaped laterally instead of flowing out the outlet pipe and through the gage.) 


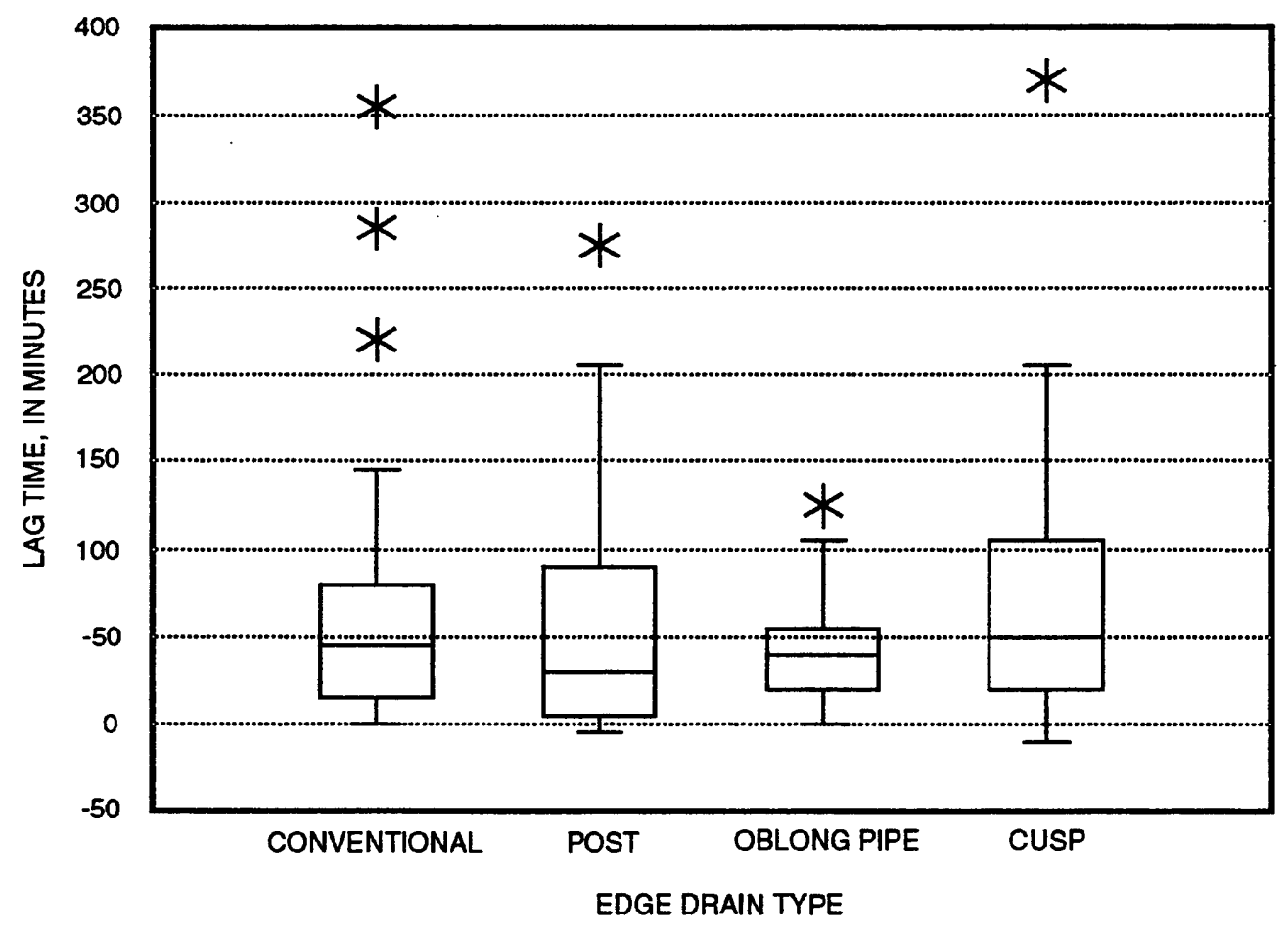

EXPLANATION

* Data point is greater than
1.5 times the interquartile range from the box.

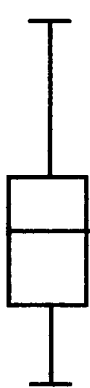

Largest data point less

than or equal to the upper

quartile plus 1.5 times the interquartile range.

$75^{\text {th }}$ Percentile

Median

$25^{\text {th }}$ Percentile

Smallest data point

greater than or equal to the lower quartile minus 1.5 times the interquartile range.

Figure 11. Distribution of lag time between rainfall and maximum discharge for each edge drain for 51 events, 1991-93 for State Route 16 near Granville, Ohio. (All edge drains were installed under nearly equal geological and environmental conditions; however, a hole in the embankment was discovered approximately 41 feet from the upper observation port of the cusp edge drain (fig. 3). Some water flowing from the edge drain may have escaped laterally instead of flowing out the outlet pipe and through the gage.) 
The coefficients of variation among the edge drains were approximately the same. The differences in the ranges of data for the lag times were notable, as shown in the box plots for the centroid to centroid lag time (fig. 10). The median and the interquartile range are smaller for the post edge drain than all the other edge drains, however, this lag time could be misleading. The discharge volumes were smaller for the post edge drain than for the other edge drains. There usually was not a long recession curve for the discharge hydrograph of the post edge drain. The small volumes and short recession curve were a significant reason for the shorter lag times and lower range of lag times for the post edge drain.

The other lag time used for the comparison of the four edge drains was the time from the rainfall onset to maximum discharge for each edge drain. These lag times demonstrate the short response time and indicate how quickly water was infiltrating into the edge drains. The oblong-pipe edge drain had the shortest mean lag time for this event characteristic among the four edge drains (table 5).

Table 5. Statistics for lag times between rainfall onset and discharge maximum for each edge drain for 51 events, 1991-93 for State Route 16 near Granville, Ohio [All units are in minutes and rounded to 3 significant digits; CV is the coefficient of variation; IQR is the interquartile range; Range is the maximum value minus the minimum value; Midrange is the value midway between the maximum and minimum values]

\begin{tabular}{|c|c|c|c|c|}
\hline \multirow[b]{2}{*}{ Statistic } & \multicolumn{4}{|c|}{ Edge drain type } \\
\hline & $\begin{array}{l}\text { Conven- } \\
\text { tional }\end{array}$ & Post & $\begin{array}{c}\text { Oblong } \\
\text { pipe }\end{array}$ & Cusp 1 \\
\hline Mean & 60.9 & 53.5 & 42.4 & 71.2 \\
\hline \multicolumn{5}{|l|}{ Standard } \\
\hline $\mathrm{CV}$ & 1.11 & 1.10 & .654 & .928 \\
\hline Minimum & 0 & 0 & 0 & 0 \\
\hline Maximum & 355 & 275 & 125 & 370 \\
\hline Median & 45 & 30 & 40 & 50 \\
\hline IQR & 65 & 85 & 35 & 85 \\
\hline 25th percentil & le 15 & 5 & 20 & 20 \\
\hline 75th percentil & le 80 & 90 & 55 & 105 \\
\hline Range & 355 & 275 & 125 & 370 \\
\hline Midrange & 178 & 138 & 62.5 & 185 \\
\hline
\end{tabular}

${ }^{1}$ All edge drains were installed under nearly equal geological and environmental conditions; however, a hole in the embankment was discovered approximately 41 feet from the upper observation port of the cusp edge drain (fig. 3). Some water flowing from the edge drain may have escaped laterally instead of flowing out the outlet pipe and through the gage.
It also had the smallest coefficient of variation. The edge drains generally produced their maximum discharge shortly after the onset of rain. During some events, however, the maximum discharge did not occur at the initial peak but much later in the event. These delayed maximum discharges increased the variability of the data. Because of these longer lag times, the medians for this event characteristic are more appropriate for comparison than the means. The post edge drain had the lowest median among the four edge drains. A box plot (fig. 11) illustrates the differences in the data sets of the four edge drains.

\section{SUMMARY}

The presentation of three geocomposite edge drains and a conventional edge drain on State Route 16 near Granville, Ohio, were based on their performance in the field. All geological and environmental conditions were as similar as possible for these comparisons. The cusp edge drain, however, might have been kinked near the upper observation port during installation. This kink reduced the discharge characteristics by an unknown amount. In addition, a sag in the conventional edge drain had an unknown effect on the discharge characteristics.

The rainfall-runoff events chosen for the analysis were carefully selected on the assumption that all gages were functioning properly for the event characteristics being compared. The comparisons of the maximum discharges for the edge drains were based on 72 events. The volumes were computed from the discharge data and compared for 55 events. For the analysis of the lag times, 51 events were used.

In general, the conventional edge drain was the most closely matched by the oblong-pipe edge drain. Most of the event characteristics for the conventional and oblong-pipe edge drain were similar for every event. The maximum discharges for the conventional and oblong-pipe edge drains were significantly higher than those for the post and cusp edge drains. The means of the maximum discharge data sets of the conventional and oblong-pipe edge drains were almost equal, and both were more than two times the means of the post and cusp edge 
drains. The median for the oblong-pipe, however, was higher than that of the conventional edge drain.

The results of the volumes comparison were similar to the results of the maximum-discharge comparison. The conventional and oblong-pipe edge drains produced the highest volumes and highest percentages of rain volumes among the four edge drains. The mean and median for the oblong-pipe, however, were slightly higher than those of the conventional edge drain. The means of the discharge volumes as a percentage of the rainfall volumes were all relatively low (less than 20 percent) because most of the rain falling on the highway was assumed to have bypassed the edge drains. The post edge drain had the smallest volumes and percentages of rain volume among all four edge drains.

The lag times for the conventional and oblongpipe edge drains were also similar for most of the event characteristics compared. The mean and median of the conventional edge drain were slightly shorter than those of the oblong-pipe edge drain for most of the lag times computed; however, the post edge drain usually had the shortest lag time for most of the selected event characteristics. This finding could be attributed to the small amount of discharge from the post edge drain. The only lag time that does not follow this general pattern is the rainfall onset to maximum discharge lag time. The oblong-pipe edge drain usually had the shortest lag time for this event characteristic.

\section{REFERENCES CITED}

Jeffcoat, H.H., Kilpatrick, F.A., Atkins, J.B., and Pearman, J.L., 1992, Effectiveness of highway edge drains: U.S. Geological Survey Water-Resources Investigations Report 92-4147, 79 p.

Hinshaw, K.T., 1988, Hydraway edge drain in Ohio, in National Research Council, Transportation Research Board, Prefabricate Washington, D.C., Transportation Research Record 1159, p. 30-38. 